\title{
Treatment of an Atrophic Scar with Fractional Carbon Dioxide Laser-assisted Poly-L-lactic Acid Delivery
}

Wan Jin Kim ${ }^{1}$

Ha Rin Jung ${ }^{2}$

Sang Ju Lee ${ }^{3}$

Han Kyoung $\mathrm{Cho}^{1}$

${ }^{1}$ Department of Dermatology, Hanyang University Medical Center, Myongji Hospital, Goyang, Korea ${ }^{2}$ Ernest Mario School of Pharmacy, Rutgers University, Piscataway, NJ, USA

${ }^{3}$ Yonsei Star Skin and Laser Clinic, Seoul, Korea
Received July 12, 2021

Accepted August 16, 2021

\footnotetext{
Correspondence

Han Kyoung Cho

Department of Dermatology, Hanyang University Medical Center, Myongji Hospital, 55 Hwasu-ro, 14 beon-gil, Deogyang-gu, Goyang 10475, Korea Tel.: +82-31-810-7050

Fax: +82-31-810-7057

E-mail: trpchkahanmail.net

(C) Korean Society for Laser Medicine and Surgery

(@) This is an open access article distributed under the terms of the Creative Commons Attribution NonCommercial License (http://creativecommons.org/ licenses/by-nc/4.0) which permits unrestricted noncommercial use, distribution, and reproduction in any medium, provided the original work is properly cited.
}

\begin{abstract}
Scars can cause great psychological stress among patients. Currently, there are numerous topical agents, laser and surgical treatments available for skin rejuvenation and scar minimization. Laser-assisted drug delivery (LADD) is a treatment method that increases drug delivery by stimulating the skin physically and chemically to enhance the penetration of topical agents. This is one of the areas of great interest in the treatment of various skin diseases in addition to its use for cosmetic purposes. In particular, LADD is relatively non-invasive and has advantages in terms of accessibility and stability. Poly-L-lactic acid (PLLA) is a collagen stimulator known to gradually restore skin volume by inducing inflammation and fibroplasia. Herein, we report a case of treatment of an atrophic scar with fractional carbon dioxide laserassisted PLLA delivery.
\end{abstract}

\section{Key words}

Atrophic scar; Fractional carbon dioxide laser; Laser-assisted drug delivery; Poly-L-lactic acid 


\section{INTRODUCTION}

Topical agents have limitations in absorption through the epidermis owing to the skin barrier.' Therefore, various techniques, such as microneedling and laser treatment, have been studied to compensate for this. ${ }^{2}$ One of the currently most popular methods is laser-assisted drug delivery (LADD), which is expected to be effective by creating microscopic treatment zones (MTZs) on the skin, with fractional carbon dioxide $\left(\mathrm{CO}_{2}\right)$ and erbium-doped yttrium-aluminum-garnet (Er:YAG) laser. ${ }^{3}$ It is a promising technique that improves the absorption of local molecules through lasers, creating synergistic therapeutic effects. ${ }^{4}$ In addition to cosmetic purposes, such as skin rejuvenation and scar regeneration, LADD can be extensively applied to treat various skin diseases, including photodamage, neoplasia, vitiligo, and onychomycosis. ${ }^{4,5}$

Herein, we present a case of a hypopigmented atrophic and depressed scar in a 21-year-old woman who was

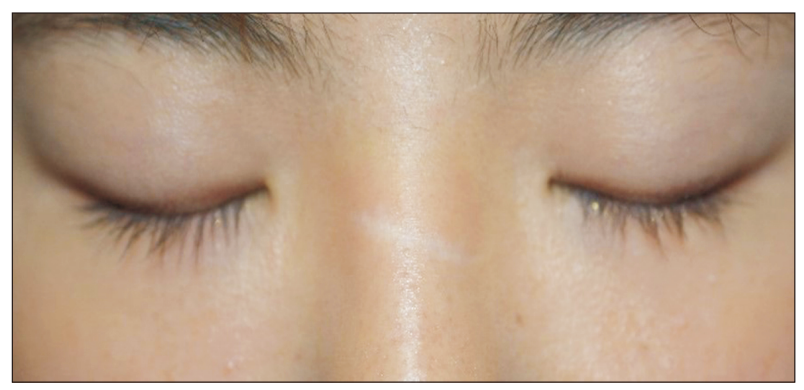

Fig. 1. A distinct 2-cm linear, hypopigmented atrophic, and depressed scar is observed across the bridge of the nose.

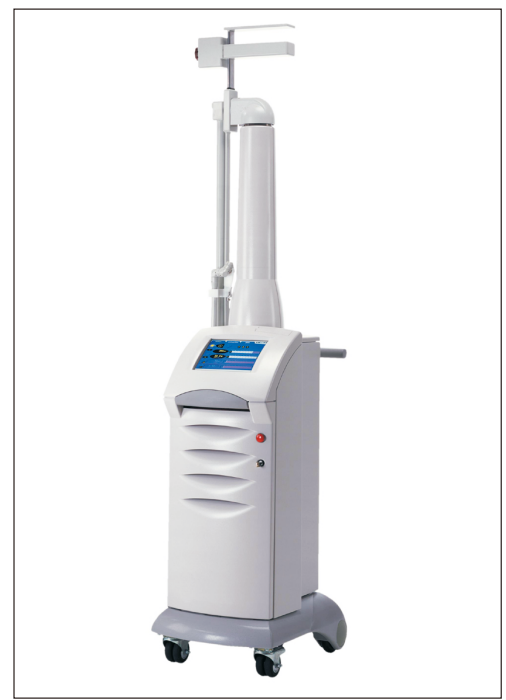

Fig. 2. Fractional carbon dioxide laser. treated with fractional $\mathrm{CO}_{2}$ laser-assisted poly-L-lactic acid (PLLA) delivery.

\section{CASE REPORT}

A 21-year-old woman presented with complaints of an atrophic and depressed scar on her nose owing to a fall at the age of 5 years. At the time of the traumatic event, no special scar treatment was performed, except for a simple treatment for wound recovery. She had no remarkable medical or family history. A distinct 2-cm linear, hypopigmented atrophic, and depressed scar was observed across the bridge of the nose (Fig. 1).

After obtaining informed consent, we performed a total of two laser treatments on the scar area at 2-month intervals. The laser used was a fractional $\mathrm{CO}_{2}$ laser (ULtraPulse ${ }^{\circledR}$ Encore laser, Lumenis, Inc., Santa Clara, CA, USA; Fig. 2). The parameters of the laser were as follows:

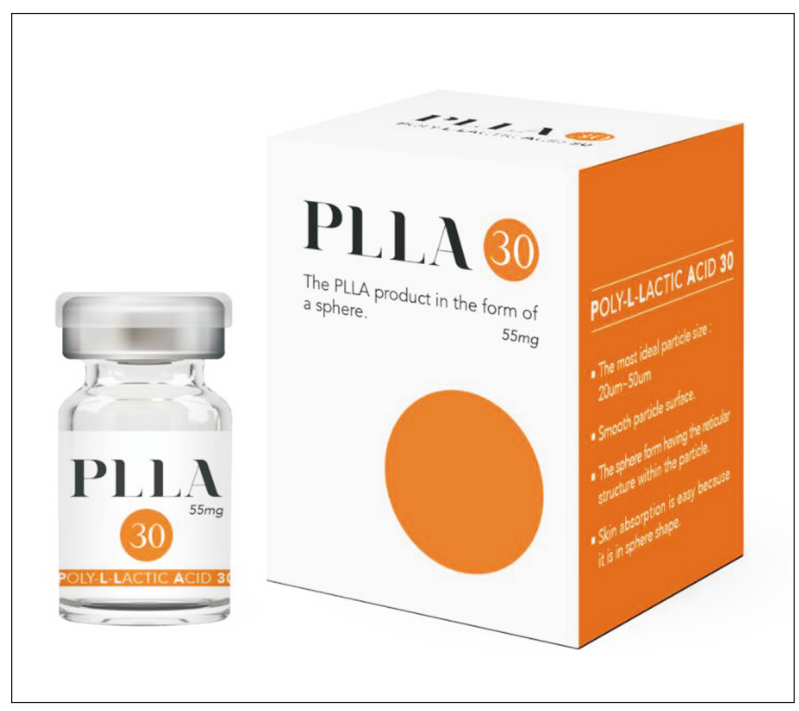

Fig. 3. Poly-L-lactic acid.

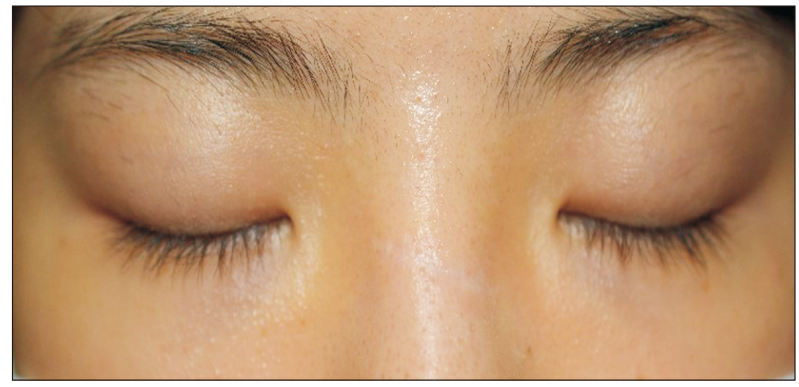

Fig. 4. After two laser treatments, the color of the hypopigmented atrophic and depressed scar became similar to the existing skin color, and the scar improved significantly. 
120- $\mathrm{mm}$ spot size, SCAAR FX'M mode, 60 mJ, 1\% coverage, and 1 pass. The laser was applied directly to the scar tissue. PLLA (PLLA30 ${ }^{\circledR}$; SimfleStick, Inc., Daegu, Korea; Fig. 3) was mixed with $3 \mathrm{cc}$ sterile water, and it was applied enough to wet the laser-treated area. The particle size of PLLA was 30-50 $\mu \mathrm{m}$. The patient did not have any restrictions on daily life. After laser treatment, the scar improved significantly, even visually (Fig. 4).

\section{DISCUSSION}

Atrophic scars are caused mainly by inflammatory skin diseases and trauma, resulting in skin collagen destruction and deficiency. ${ }^{6,7}$ Lasers are commonly used for scar treatment, along with simple resection, peeling procedures, and filler injection. Surgical procedures have significant side effects and are not suitable for scars of small size and a small degree of atrophy. Filler injection procedures are disadvantageous for fine scar correction, and it is difficult to achieve permanent effects. Laser treatment is advantageous for small, shallow scar correction and can achieve permanent effects; however, treatment is usually prolonged because repeated treatment is required. The principle of atrophic scar treatment is to increase collagen in the dermis, and the types of lasers that can be used are non-invasive lasers and fractional $\mathrm{CO}_{2}$ lasers. However, even with laser treatment, the effect of skin restoration is limited. ${ }^{7-9}$

Therefore, the LADD method, which combines topical agents that can help with wound healing with laser treatment, is a very promising technique of recent interest that improves the absorption of small molecules to create synergies in therapeutic effects. Through fractional $\mathrm{CO}_{2}$ and Er:YAG lasers, microthermal injury occurs, which creates spatially distributed columns, eventually forming MTZs. ${ }^{3}$ Since the laser used partially irradiates the skin, most of the surrounding skin that has not been irradiated remains intact, while the irradiated area allows relatively deep penetration to the dermis. ${ }^{10}$

In addition to cosmetic purposes, such as skin rejuvenation and scar regeneration, ${ }^{11,12}$ LADD can be extensively applied to treat various skin diseases, including photodamage, neoplasia, vitiligo, or onychomycosis. ${ }^{4,5}$ Some of the drugs that can be used with LADD include corticosteroids, methotrexate, 5-fluorouracil, amorolfine, and PLLA. LADD is non-invasive and superior in terms of accessibility and has fewer systemic side effects than other surgical procedures. $^{5}$

Recently, there have been reports of applying PLLA to treat atrophic scars, which helps to produce collagen after fractional $\mathrm{CO}_{2}$ laser treatment. PLLA is a synthetic substance that not only acts as a filler for subcutaneous injection but also promotes collagen production and vascularization; histological findings have shown that skin thickness increases after treatment. ${ }^{13,14}$ PLLA is usually limited in its absorption into the skin owing to its large particle size. To overcome this, we set the spot size of fractional $\mathrm{CO}_{2}$ to $120 \mu \mathrm{m}$ and used a tightly controlled size of 30-50- $\mu \mathrm{m}$ PLLA to complement the existing large particle size. Furthermore, the spherical and smooth surface of the particle was used to easily respond to implantation on the skin without inducing inflammatory reactions. ${ }^{15}$ In contrast, less than $30 \mu \mathrm{m}$ of the particle size is known to be phagocytosed by macrophages, making it difficult to work. ${ }^{13}$ Therefore, selecting particles that are well absorbed into the skin, but with the appropriate size, is crucial for planning treatment.

PLLA and LADD have been used for cosmetic purposes for many years; however, there is still a lack of protocols established when combining the two, and clinical applications are still under study. ${ }^{3}$

Herein, we report a case of treatment of an atrophic scar with fractional $\mathrm{CO}_{2}$ laser-assisted PLLA delivery. We found that fractional $\mathrm{CO}_{2}$ laser and PLLA application via LADD was effective in our patient with a scar. PLLA, which promotes collagen production, was used in a smaller size and applied via LADD, which was judged to be more effective in the treatment of the scar. We then assume that $L A D D$ yields better results than does laser treatment alone.

\section{CONFLICT OF INTEREST}

No potential conflict of interest relevant to this article was reported.

\section{FUNDING}

None.

\section{REFERENCES}

1. Alegre-Sánchez A, Jiménez-Gómez N, Boixeda P. Laserassisted drug delivery. Actas Dermosifiliogr (Engl Ed) 2018;109:858-67.

2. Badran KW, Nabili V. Lasers, microneedling, and platelet-rich plasma for skin rejuvenation and repair. Facial Plast Surg Clin North Am 2018;26:455-68.

3. Ibrahim O, Wenande E, Hogan S, Arndt KA, Haedersdal M, Dover JS. Challenges to laser-assisted drug delivery: applying 
theory to clinical practice. Lasers Surg Med 2018;50:20-7.

4. Wenande E, Erlendsson AM, Haedersdal M. Opportunities for laser-assisted drug delivery in the treatment of cutaneous disorders. Semin Cutan Med Surg 2017;36:192-201.

5. Waibel JS, Rudnick A, Shagalov DR, Nicolazzo DM. Update of ablative fractionated lasers to enhance cutaneous topical drug delivery. Adv Ther 2017;34:1840-9.

6. Newberry Cl, Thomas JR, Cerrati EW. Facial scar improvement procedures. Facial Plast Surg 2018;34:448-57.

7. Mcllwee BE, Alster TS. Laser skin resurfacing: cosmetic and medical applications. In: Kang S, Amagai M, Bruckner AL, Enk AH, Margolis DJ, McMichael AJ, et al., editors. Fitzpatrick's Dermatology. 9th ed. New York: McGraw-Hill; 2019. p.3834-45.

8. Spicer MS, Goldberg DJ. Lasers in dermatology. J Am Acad Dermatol 1996;34:1-25; quiz 26-8.

9. Tanzi EL, Lupton JR, Alster TS. Lasers in dermatology: four decades of progress. J Am Acad Dermatol 2003;49:1-31; quiz 314.

10. Manstein D, Herron GS, Sink RK, Tanner H, Anderson RR. Fractional photothermolysis: a new concept for cutaneous remodeling using microscopic patterns of thermal injury. Lasers Surg Med 2004;34:426-38.
11. Waibel JS, Wulkan AJ, Shumaker PR. Treatment of hypertrophic scars using laser and laser assisted corticosteroid delivery. Lasers Surg Med 2013;45:135-40.

12. Rkein A, Ozog D, Waibel JS. Treatment of atrophic scars with fractionated CO2 laser facilitating delivery of topically applied poly-L-lactic acid. Dermatol Surg 2014;40:624-31.

13. Fitzgerald R, Bass LM, Goldberg DJ, Graivier MH, Lorenc ZP. Physiochemical characteristics of poly-l-lactic acid (PLLA). Aesthet Surg J 2018;38(suppl_1):S13-7.

14. Ibrahim O, Ionta S, Depina J, Petrell K, Arndt KA, Dover JS. Safety of laser-assisted delivery of topical poly-l-lactic acid in the treatment of upper lip rhytides: a prospective, rater-blinded study. Dermatol Surg 2019;45:968-74.

15. Lemperle G, Morhenn VB, Pestonjamasp V, Gallo RL. Migration studies and histology of injectable microspheres of different sizes in mice. Plast Reconstr Surg 2004;113:1380-90.

How to cite this article: Kim WJ, Jung HR, Lee SJ, Cho HK. Treatment of an atrophic scar with fractional carbon dioxide laser-assisted poly-L-lactic acid delivery. Med Lasers 2021;10:181184. https://doi.org/10.25289/ML.2021.10.3.181 